\title{
Guido Freckmann* \\ Basics and use of continuous glucose monitoring (CGM) in diabetes therapy
}

https://doi.org/10.1515/labmed-2019-0189

Received November 7, 2019; accepted December 11, 2019; previously published online February 4, 2020

\begin{abstract}
Background: For a long time, self-monitoring of blood glucose (SMBG) was widely viewed as the essential glucose measurement procedure in the therapy of insulin-treated people with diabetes. With increasing accuracy and simplified handling of continuous glucose monitoring (CGM) systems, this evolving technology challenges and at least partly replaces SMBG systems.

Content: Sensors of all currently available CGM systems measure glucose levels in the subcutaneous interstitial fluid for 6-14 days. The only available implantable sensor facilitates a measurement span of up to 6 months. Depending on the used system, glucose levels are either shown in real time (rtCGM systems) or after scanning (iscCGM systems). Functions such as alerts, alarms and trend arrows and data presentation encourage independent self-management of diabetes therapy. The high frequency of glucose data and the multitude of existing functions require an extensive training of people with diabetes and their caregivers.
\end{abstract}

Summary: CGM systems provide a much more detailed picture of glycemia in people with diabetes. Educated patients can use these data to react adequately to their glucose levels and therefore avoid hypoglycemic and hyperglycemic events. Studies showed that glycated hemoglobin $\left(\mathrm{HbA}_{1 \mathrm{c}}\right)$ levels and hypoglycemic events can be significantly reduced by frequent use of CGM systems.

Keywords: blood glucose; continuous glucose monitoring; diabetes; glycemic variability; hypoglycemia; mean absolute relative difference.

\footnotetext{
*Correspondence: Guido Freckmann, Institut für DiabetesTechnologie, Forschungs- und Entwicklungsgesellschaft mbH an der Universität Ulm, Lise-Meitner-Str. 8/2, 89081 Ulm, Germany, E-Mail: guido.freckmann@idt-ulm.de.https://orcid.org/0000-00020406-9529
}

¿ Open Access. ( 2020 Guido Freckmann, published by De Gruyter. (cc) BY Public License.

\section{Background}

Regular measurement of blood glucose (BG) levels by selfmonitoring of blood glucose (SMBG) is a prerequisite for an adequate therapeutic treatment of patients with diabetes mellitus, especially for those with an intensified insulin therapy, for example patients with type 1 diabetes [1]. SMBG systems are essential tools in intensified insulin therapy of people with diabetes, because they provide the possibility to calculate bolus doses for carbohydrate intake, as well as the detection and subsequent counteraction of hypo- or hyperglycemia [2]. The amount of usually performed measurements per day, however, is too low to allow a statement about the kinetics of $B G$ and therefore only represents a snapshot of the actual glycemic status. Furthermore, SMBG requires a fingerstick to obtain a blood sample, which can be painful and time-consuming, subsequently leading to poor compliance [3]. In addition, dysglycemic events, for example nocturnal or asymptomatic hypoglycemia, may not be recognized and consequently threaten the health of people with diabetes [4]. Severe hypoglycemia can lead to coma or death and has been linked to increased mortality $[1,5]$. Fear of hypoglycemia often leads to a rethinking of patients in the direction of an acceptance of higher BG levels, and subsequently increased glycated hemoglobin $\left(\mathrm{HbA}_{1 \mathrm{c}}\right)$ values, to avoid the risk of getting into a state of hypoglycemia. However, increased $\mathrm{HbA}_{1 \mathrm{c}}$ levels are related to short- and long-term complications and diseases, and should be consequently reduced to close-to-normal levels.

Since the first continuous glucose monitoring (CGM) system, developed in the early 1990s [6] and marketed in 1999, many developmental steps of CGM systems were performed. Current CGM systems are smaller, have lower weight, are easier to use, have a prolonged wearing time and are more accurate than older ones [7]. All of these systems continuously measure the glucose concentration in the interstitial fluid and transfer the data via a transmitter to a receiver which displays the results. In the past, all CGM systems were intended by their manufacturers for adjunctive use in addition to SMBG measurements, because accuracy was not sufficient for making treatment decisions. Since a few years, some devices (see section 
"Current status of CGM") are claimed for non-adjunctive use due to their improved accuracy [8]. Nevertheless, the point accuracy of CGM systems remains still behind that of SMBG systems.

\section{Content}

\section{Current status of CGM}

CGM systems typically consist of the following three components: (a) a glucose oxidase (GOD)-based glucose sensor which is inserted into the subcutaneous fatty tissue and continuously measures glucose concentration in the interstitial fluid, (b) a transmitter which is attached to the sensor and transfers the data to (c) a receiver/smartphone which displays the results (Figure 1). Glucose concentration is estimated based on the production of hydrogen peroxide by GOD and the associated release of electric current, which is directly proportional to the concentration of glucose in the interstitial fluid. In detail, GOD and its cofactor, which works as the initial electron acceptor, catalyze the oxidation of glucose to hydrogen peroxide $\left(\mathrm{H}_{2} \mathrm{O}_{2}\right)$ and gluconic acid, whereas the cofactor is reduced: Glucose $+\mathrm{GOD}-$ cofactor $_{\text {(oxidized) }} \rightarrow$ Gluconic acid+GOD- cofactor $_{\text {(reduced) }}$. The cofactor is regenerated in a reaction with oxygen $\left(\mathrm{O}_{2}\right)$, which leads to the formation of $\mathrm{H}_{2} \mathrm{O}_{2}$ : GOD - cofactor ${ }_{\text {(reduced) }}+\mathrm{O}_{2} \rightarrow \mathrm{GOD}-$ cofactor $_{\text {(oxidized) }}+\mathrm{H}_{2} \mathrm{O}_{2} \cdot \mathrm{H}_{2} \mathrm{O}_{2}$ is oxidized at a catalytic electrode where the amount of transferred electrons is detected: $\mathrm{H}_{2} \mathrm{O}_{2} \rightarrow 2 \mathrm{H}^{+}+\mathrm{O}_{2}+2 \mathrm{e}^{-}$. This electron flow is proportional to the glucose concentration in the interstitial fluid. Currently, two different types of CGM systems are available on the market: real-time continuous glucose monitoring (rtCGM) systems and intermittently scanned continuous glucose monitoring (iscCGM, flash glucose monitoring [FGM]) systems. rtCGM systems measure the

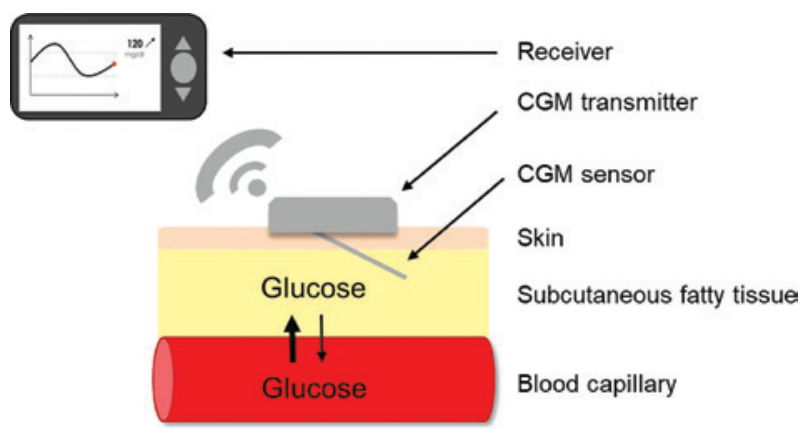

Figure 1: Components of a CGM system (scheme). glucose values and automatically display, e.g. every $5 \mathrm{~min}$, a recent value. In contrast, the sensor of iscCGM systems measures glucose levels every minute and stores one value every $15 \mathrm{~min}$. iscCGM systems need to be actively scanned to obtain glucose information and to show it on the device display. The scans have to be performed at least every $8 \mathrm{~h}$ to retain the whole daily glycemic data [7]. Scanned glucose values of iscCGM systems can be either downloaded to a personal computer or uploaded to a cloud-based system [9].

Typical sensor application sites for rtCGM systems, such as Dexcom $\mathrm{G6}^{\circledast}$, are abdomen and upper arm for iscCGM systems, such as FreeStyle ${ }^{\circledR}$ Libre 2. However, in order to allow a correct determination of the glucose values, sensors may only be used at the approved application sites.

The sensor wear time of non-implantable sensors is limited to up to 10 days for rtCGM systems and to 14 days for iscCGM systems. In contrast, the sensor wear time of implantable, fluorescence-based sensors, like in the case of the rtCGM system Eversense ${ }^{\circledR} /$ Eversense $^{\circledR} \mathrm{XL}$, is 90 up to 180 days (Table 1) [10]. All rtCGM systems, except for Dexcoms' current G6 ${ }^{\circledR}$ system, have to be manually calibrated to BG levels approximately 2 times per day (see also section "Sensor calibration"). The iscCGM systems provide factory calibration and therefore do not need SMBG measurements for calibration. Also, the Dexcom $\mathrm{G} 6^{\circledR}$ provides a factory calibration with the option of additional fingerstick calibration. The CGM devices Dexcom G5 ${ }^{\circledR}$ and $G 6^{\circledR}$, as well as FreeStyle ${ }^{\circledR}$ Libre and FreeStyle ${ }^{\circledR}$ Libre 2, are claimed by their manufacturers as a replacement of fingerstick testing for diabetes treatment decisions [8].

Unlike current iscCGM systems, most rtCGM systems can be linked to insulin pumps, representing so-called (hybrid) closed-loop systems. A sensor-augmented pump system displays CGM data on the screen of the insulin pump and enables patients to manually adapt insulin doses based on the current glucose value. Some of these pump systems already use a low glycemic suspend to stop basal rate for up to $2 \mathrm{~h}$ if glucose is low [11]. Recently, the first sensor-integrated pump systems that automatically adapt basal insulin delivery by the pump based on CGM data became available. This helps to achieve a consistent glucose profile and might reduce the incidence of hypoglycemic events, especially during night [12].

\section{Clinical benefits of CGM}

Various studies demonstrated the benefits of CGM systems in diabetes therapy $[9,13,14]$, whereby the 
number of hypoglycemic events could be decreased and glycemic control could be improved. In addition, a significant reduction in $\mathrm{HbA}_{1 \mathrm{c}}(1.0 \%$ reduction from baseline versus $0.4 \% ; \mathrm{p}<0.001)$ and a decreased time spent out of the desired target glucose range (37 $\mathrm{min} /$ day less time spent $<70 \mathrm{mg} / \mathrm{dL} ; \mathrm{p}=0.002$ ) were shown [13]. Further studies have evaluated the effectiveness of CGM systems in helping patients with a history of severe hypoglycemia events or impaired hypoglycemia awareness [15]. For example, in a 6-month, multicenter study with type 1 diabetes patients and a history of impaired hypoglycemia awareness or severe hypoglycemia, performed in 12 diabetes practices in Germany, the so-called HypoDE study, a significantly reduced incidence of hypoglycemia events by $72 \%(\mathrm{p}<0.0001)$ was observed for the use of CGM compared to SMBG [15]. In addition, clinical trials have shown that use of CGM systems may also attenuate the fear of hypoglycemia events and diabetes-related stress and therefore improve quality of life [16]. Not only rtCGM systems, but also iscCGM systems showed a reduction in $\mathrm{HbA}_{1 \mathrm{c}}$ levels, both in patients with type 1 diabetes and type 2 diabetes, compared to SMBG systems. Furthermore, iscCGM was positively correlated with the time spent in euglycemia and inversely associated with the time spent in hypo- or hyperglycemia [17].

Even though the use of CGM systems shows several benefits, you still have to take into account that the results of CGM studies are dependent on various factors, such as study design, study patient population and the CGM system used (see also section "Sensor metrics and accuracy”). For example, time below the range $(<70 \mathrm{mg} / \mathrm{dL})$ differs for people with diabetes between different studies, whereas $\mathrm{HbA}_{1 \mathrm{c}}$ and the number of patients was similar [17]. One explanation for these varying results could be the differences in the patient population between these studies, e.g. different inclusion or exclusion criteria, or the differences between the accuracy of the used rtCGM and iscCGM systems.

\section{Alerts, alarms and trend arrows}

One feature of rtCGM systems is the availability of programmable alerts and alarms, which warn of impending or occurring hypo- or hyperglycemia events (Table 1). As a result, rapidly increasing or decreasing glucose levels can be noticed and subsequently counteracted. With the launch of Abbotts' Freestyle ${ }^{\circledR}$ Libre 2, an alarm function has been added to this iscCGM system; however, a scan after the alarm to provide the glucose value is still necessary. Through the early perception of changing glucose 
levels, the probability of nocturnal hypoglycemic events [18], as well as missed bolus insulin injections for meals, can be reduced. Nonetheless, excessive occurrence of alarms can also lead to reduced compliance in patients ("alarm fatigue") [19].

Not only alerts and alarms, but also trend arrows in CGM systems serve as an early warning for impending hypoglycemia and hyperglycemia events. Downward trend arrows appear when glucose level is falling, whereas upward arrows appear when it is rising. Consequently, the trend arrows may indicate the need to ingest carbohydrates or for correcting insulin dose. However, trend arrows do not always match future glucose change, especially in the first hours after carbohydrate intake or insulin delivery [20]; therefore, this has to be considered in the correct interpretation of trend arrows and subsequent therapy decisions. Furthermore, trend arrows are not standardized among CGM systems from different manufacturers and can therefore not be compared. For example, two upward arrows in the Guardian ${ }^{\mathrm{TM}}$ Connect system indicate a glucose rising of about $2-3 \mathrm{mg} / \mathrm{dL} / \mathrm{min}$, whereas the Dexcom $\mathrm{G}^{\circledR}{ }^{\circledR}$ system displays only one arrow for that case. In addition, rapidly rising or falling glucose levels $(>3 \mathrm{mg} / \mathrm{dL} / \mathrm{min})$ are not indicated with certain trend arrows by the Eversense ${ }^{\circledR}$ and FreeStyle ${ }^{\circledR}$ Libre systems. That is one important reason why patients and their caregivers should be trained in detail with their specific CGM system.

\section{CGM measurement compartment}

Glucose results of SMBG systems are accomplished by multiple daily capillary BG measurements. Each measurement procedure requires fingersticks to get capillary blood. In contrast to that, CGM measures in the subcutaneous interstitial fluid. The CGM device displays a measurement result that is calculated by an algorithm based on tissue glucose and BG values (capillary glucose values) used for calibration. The diffusion of glucose from the intravascular to the subcutaneous interstitial fluid compartment leads to a physiologic delay (Figure 1), whereas the processing of the gained data results in a technological delay, whereby a time lag between the measurement and display of the result occurs [21]. The physiological time lag amounts to around 7-8 $\mathrm{min}$ [22] and the technological time lag amounts to around $4-6 \mathrm{~min}[23,24]$. The algorithms of currently used CGM systems intend not only to correctly calculate a tissue glucose value approximated to the capillary BG value, but also to reduce the time lag to a minimum.

\section{Sensor calibration}

Sensor calibration of CGM systems is necessary to convert the signal of the electric current into the corresponding glucose concentration. This calibration is performed either during the manufacturing process, for example in the case of Dexcom G6 ${ }^{\circledR}$ and FreeStyle ${ }^{\circledR}$ Libre/Libre 2, or implemented by users themselves, or both. In factorycalibrated CGM systems, the sensitivity of the sensor is determined by a sensor code which is preprogrammed into its electronic. Most of the current rtCGM systems require user calibration against a capillary BG measurement result every $12 \mathrm{~h}$, which has to be entered by the user (Table 1). Therefore, the accuracy of a CGM system is directly dependent and determined by the accuracy of the used SMBG system. In addition, accuracy can be also affected by choosing an inadequate point of time for calibration, for example during rapidly changing glucose levels [25], or by user mistakes. Calibration errors will have an impact at least until the next calibration occurs. In factory-calibrated CGM systems, this calibration step is not required, whereby potential handling and transcription errors are excluded. However, because these systems do not offer the possibility of correction, a sensor has to be replaced by a new one if it turns out to be biased [26]. The combination of a factory-calibrated sensor, which can be manually re-calibrated if necessary, such as that implemented in the Dexcom $\mathrm{G}^{\circledR}{ }^{\circledR}$ system, could furthermore increase the accuracy of the sensor by re-calibration [27].

\section{Sensor metrics and accuracy}

In contrast to SMBG systems, there is neither a generally accepted metric available, nor requirements to determine and compare the accuracy of CGM systems reproducibly. Often the number of CGM values within $20 \mathrm{mg} / \mathrm{dL}$ or $20 \%$ of reference values [28], corresponding to the accuracy criteria of SMBG systems (for example $\pm 15 \mathrm{mg} / \mathrm{dL}$ or $\pm 15 \%$, respectively $\pm 10 \mathrm{mg} / \mathrm{dL}$ or $\pm 10 \%$ ), or the mean absolute relative difference (MARD), are used for accuracy reporting.

MARD is calculated by averaging the absolute values of relative differences between CGM system measurement results and corresponding comparison method results, mainly obtained from SMBG systems. Each individual relative difference value, irrespective of whether the calculated difference with respect to the comparison result is positive or negative, is considered as a positive value. A MARD of $10 \%$ or less for a CGM system is under discussion as being accurate enough for making insulin dosing decisions based 
on the determined readings [29]. Accuracy of early sensors of CGM systems showed a MARD of nearly 20\% [30], which has been significantly improved over the last two decades. Current CGM (rtCGM and iscCGM) systems reach MARD values in the range of approximately $9 \%-14 \%$. A limiting factor of MARD is the fact that it may vary through the glucose ranges, for example in the hypoglycemic and the hyperglycemic range, and that information about the direction of the error is not provided. The higher the rates of change are, positive or negative, the higher the MARD will be. Also, other factors regarding the study design, e.g. included patients (people with type 1 or type 2 diabetes), influence the MARD. In addition, the MARD also depends on the reference measurements, which are used in different studies, and its calculation is not standardized [31]. For these reasons, the study design should be standardized. If different CGM systems are worn in parallel and compared in the same subject in so-called head-to-head studies, the MARD values between these devices are comparable. A head-to-head study from 2014, for example, showed a greater accuracy for one of the two tested devices [32], whereas a current head-to-head study from 2019 showed similar overall accuracy for all tested CGM systems (MARD: $10.1 \%-11.9 \%$ ) and that the performance of these systems was improved after the first day of use [33].

The bias is defined as the systematic difference between measurement results from the CGM system under investigation and the comparison method. The difference between bias and MARD is that the bias calculation incorporates the directionality of the difference, whether positive or negative, compared to the value of the comparison method. Bland and Altman suggested plotting individual differences between results of the investigated systems and the comparison method against their mean value, in response to limitations posed by the use of correlation methodologies in comparing two quantitative measurement systems [34].

\section{Evaluation and visualization of CGM data}

CGM provides a much larger number of glucose readings than occasional SMBG, whereby a comprehensive picture of daily glucose course is obtained. Up to 288 glucose measurement results every day (within a 5-min interval) make the use of easy understandable and standardized data readouts and graphical presentations necessary. Retrospective CGM data enable patients to enhance their glycemic management by adjustment of their therapy and behavior with the help of their clinicians under consideration of supplementary disclosures, such as insulin dosing and carbohydrate intake. These data, for example, can enable insights into the patterns of hypo- and hyperglycemia events that occur over time and lead to a change in their therapy to avoid such events in the future [35].

The ambulatory glucose profile (AGP) is generated via a combination of all data from several days or weeks and translating them into one period with a length of $24 \mathrm{~h}$ (Figure 2). Key elements of the AGP are a plotted median curve ( $50^{\text {th }}$ percentile), two curves above and below the median which represent the interquartile range (IQR), and the $10^{\text {th }}$ and $90^{\text {th }}$ percentile curves on the sides of the IQR. The IQR describes glucose variability by showing the glucose range in which $50 \%$ of all data points are located. The $50^{\text {th }}$ percentile depicts glucose stability, and the $10^{\text {th }}$ and $90^{\text {th }}$ percentile curves allow the backtracking of extreme glucose excursions. Therefore, the AGP report can serve as a fast and easy-to-assess entry point for data analysis of CGM data by physicians and caregivers [35].

The current international consensus report on use of CGM systems provides a comprehensive list of descriptions and recommendations of key metrics that should be assessed in the analysis of retrospective data and be utilized to assess glycemic control (Table 2) [36]. Data sufficiency, for example, indicates the time period (at least 10 of the 14 days of CGM use) which is necessary to receive representative data, as well as for adequate decision-making, and the coefficient of variation (\%CV) indicates the level of glycemic variability (GV) over the reported CGM time period (target $\leq 36 \%$ ). Further parameters such as glucose management indicator (GMI) and time in ranges (TiRs) have, in addition, the potential to monitor diabetes control. $\mathrm{HbA}_{1 \mathrm{c}}$ is currently used and recommended as the key laboratory parameter for monitoring diabetes [37]. $\mathrm{HbA}_{1 \mathrm{c}}$ can not only be determined directly, but also be estimated based on calculation rules and average BG levels measured by SMBG $\left(\hat{=} \mathrm{eA}_{1 \mathrm{c}}\right)$. The so-called GMI, however, calculates the estimated $A_{1 c}$ based on CGM-derived glucose values [38]. TiR describes the time that people with diabetes spend within the desired target glucose range (usually $70-180 \mathrm{mg} / \mathrm{dL}$ ). Because glucose fluctuations are captured continuously with CGM systems, this parameter is more sensitive than $\mathrm{HbA}_{1 \mathrm{c}}$ and is recommended by an international group of experts as the new key metric of glycemic control [36]. However, as TiR alone is not sufficient to describe the overall glycemic control, it is also necessary to indicate and quantitate the time below target range (TbR) and time above target range (TaR) [39]. These times in ranges enable the possibility to provide a more detailed view of GV (Figure 2). Increased $\mathrm{HbA}_{1 \mathrm{c}}$ levels are related 
A
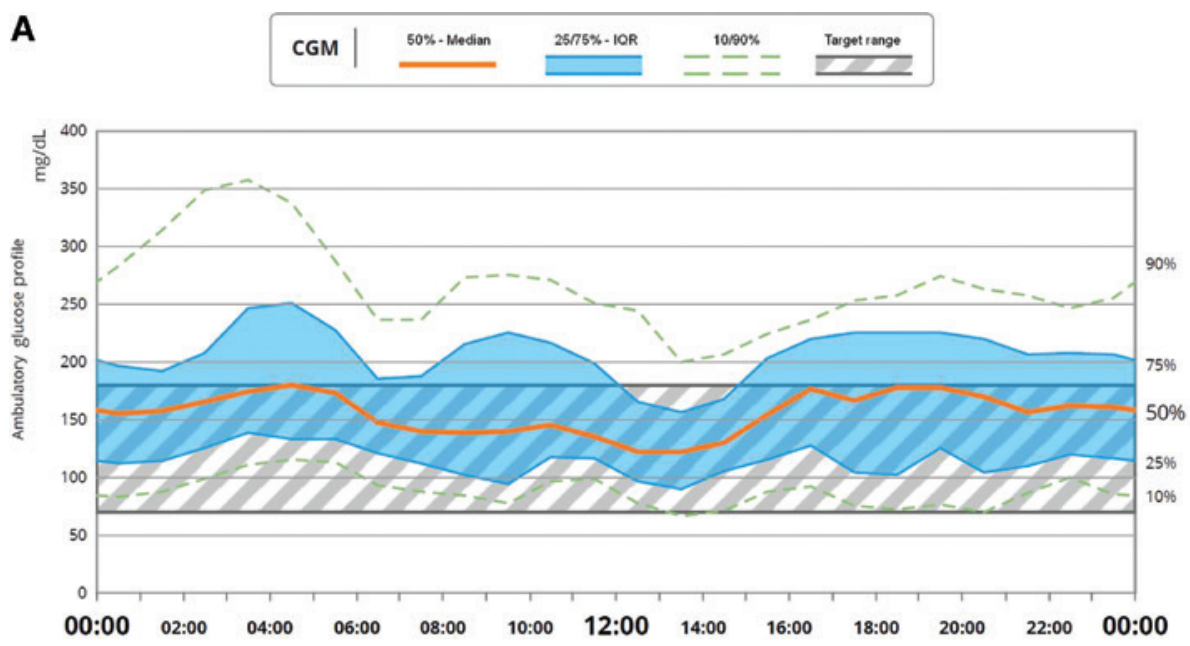

B

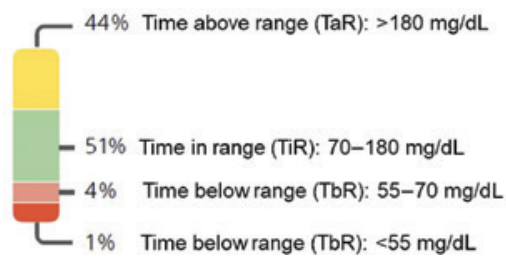

Figure 2: Dexcom CLARITY ${ }^{\circledR}$ software.

(A) Ambulatory glucose profile (AGP) generated and modified from Dexcom CLARITY ${ }^{\circledR}$ software; (B) graph represents an exemplary overview of the percentage of time spent in specific ranges (generated and modified from Dexcom CLARITY® ${ }^{\circledR}$ software).

Table 2: Key metrics for CGM data analysis and reporting [36].

\begin{tabular}{lll}
\hline$\#$ & Key metrics & \\
\hline 1 & Mean glucose, $\mathrm{mg} / \mathrm{dL}$ & \\
2 & Number of days CGM is worn (recommendation: 14 days) & \\
3 & Percentage of time CGM is active (recommendation: at least 10 from 14 days = 70\%) \\
4 & Glucose management indicator (GMI) & \\
5 & Glycemic variability $(<36 \%=$ stable, $>36 \%=$ unstable) & Level 2 \\
6 & Time above range (TaR): $\%$ of readings and time $>250 \mathrm{mg} / \mathrm{dL}$ & Level 1 \\
7 & Time above range (TaR): $\%$ of readings and time $181-250 \mathrm{mg} / \mathrm{dL}$ & In range \\
8 & Time in range (TiR): $\%$ of readings and time $70-180 \mathrm{mg} / \mathrm{dL}$ & Level 1 \\
9 & Time below range (TbR): $\%$ of readings and time $54-69 \mathrm{mg} / \mathrm{dL}$ & Level 2 \\
10 & Time below range (TbR): $\%$ of readings and time $<54 \mathrm{mg} / \mathrm{dL}$ &
\end{tabular}

to short- and long-term microvascular complications and long-term macrovascular diseases [40]. Even though there is some correlation between $\mathrm{TbR}$ and $\mathrm{HbA}_{1 \mathrm{c}}$, such a relation to clinical outcomes still remains to be established for TiR [41]. To efficiently gain control of diabetes therapy management, TiRs should be considered in addition to $\mathrm{HbA}_{1 \mathrm{c}}$ in decision-making. Although GV has also been linked to micro- and macrovascular complications and to increased mortality in people with diabetes [39, 42], no studies have been published so far which show a direct effect of a reduction of $\mathrm{GV}$ on improved clinical outcomes.

\section{Education and training}

The effective and safe use of CGM systems and the correct interpretation of provided data require that patients and caregivers are trained in using their CGM system and in interpreting the displayed data. Besides education 
materials and comprehensive training, which is offered by the manufacturers, for example FLASH (for iscCGM systems), independent training programs, for example Spectrum (for rtCGM systems), are also available [43, 44].

The training program Spectrum is offered either for parents of children with diabetes, adolescents or adults. Its aim is to mediate basic information to users of rtCGM systems and to accompany the start of the usage. During this training program, the participants are trained on the readout, analysis and course of glucose data, as well as on the setup and usage of alarms, respectively [43]. In the evaluations study of the iscCGM training program FLASH, it could be shown that clinical parameters, such as $\mathrm{HbA}_{1 c}$ and TiR (see also section "Evaluation and visualization of CGM data"), were significantly improved by participating in this training program and moreover, that the communication between patients and their caregivers was also improved [45].

\section{Summary}

Current CGM systems have the advantage that glucose levels can be monitored continuously in the course of a day. Therefore, they provide a detailed picture of patients' glucose metabolic state and enable patients to quickly react to their glucose levels and to avoid hypoglycemia and hyperglycemia events. The level of $\mathrm{HbA}_{1 \mathrm{c}}$, the key laboratory parameter for monitoring diabetes, can be significantly reduced through the use of CGM, and the risk of short- and long-term complications, and diseases, is decreased. In addition, severe glycemic events, such as nocturnal or asymptomatic hypoglycemia, and severe hypoglycemia, can be counteracted or significantly reduced, which leads to an improvement in the quality of life of people with diabetes.

For the proper use of CGM systems, to become familiar with the functions and the correct interpretation of the CGM data, as well as to perform beneficial therapeutic decisions, patients and their caregivers should read the detailed instructions provided by the manufacturers and should additionally be trained either with one of the available trainee programs or certain chapters of it.

\section{Impact statement}

1. This review presents a broad overview of the basics of continuous glucose monitoring (CGM).
2. It will improve the understanding about the use of CGM in the therapy of people with diabetes, especially of those with an intensified insulin therapy, and the resulting benefits.

3. As CGM provides lots of additional information, a replacement of $\mathrm{HbA}_{1 \mathrm{c}}$ and blood glucose values is discussed.

Acknowledgments: The author thanks Prof. Dr. med. Cornelia Haug, Delia Waldenmaier and Dr. rer. nat. Sebastian Schauer for the help and feedback in creating the manuscript.

Author contributions: The author has accepted responsibility for the entire content of this submitted manuscript and approved submission.

Research funding: None declared.

Employment or leadership: GF is general manager of the IDT (Institut für Diabetes-Technologie Forschungs- und Entwicklungsgesellschaft $\mathrm{mbH}$ an der Universität Ulm, Ulm, Germany), which carries out clinical studies on the evaluation of BG meters and medical devices for diabetes therapy on its own initiative and on behalf of various companies.

Honorarium: GF/IDT have received speakers' honoraria or consulting fees from Abbott, Ascensia, Dexcom, i-Sens, Kirchheim Verlag, Medica, Menarini Diagnostics, Metronom Health, Roche, Sanofi and Ypsomed.

Competing interests: The funding organization(s) played no role in the study design; in the collection, analysis, and interpretation of data; in the writing of the report; or in the decision to submit the report for publication.

\section{References}

1. American Diabetes Association. Standards of Medical Care in Diabetes - 2018. Diabetes Care 2018;41:S1-156.

2. Blonde L, Karter AJ. Current evidence regarding the value of selfmonitored blood glucose testing. Am J Med 2005;118:20S-6.

3. Moström P, Ahlén E, Imberg H, Hansson P-O, Lind M. Adherence of self-monitoring of blood glucose in persons with type 1 diabetes in Sweden. BMJ Open Diabetes Res Care 2017;5:e000342.

4. Gold AE, MacLeod KM, Frier BM. Frequency of severe hypoglycemia in patients with type I diabetes with impaired awareness of hypoglycemia. Diabetes Care 1994;17:697-703.

5. Khunti K, Davies M, Majeed A, Thorsted BL, Wolden ML, Paul SK. Hypoglycemia and risk of cardiovascular disease and all-cause mortality in insulin-treated people with type 1 and type 2 diabetes: a cohort study. Diabetes Care 2015;38:316-22.

6. Pfeiffer EF. The "Ulm Zucker Uhr System" and its Consequences. Horm Metab Res 1994;26:510-14. 
7. Rodbard D. Continuous glucose monitoring: a review of successes, challenges, and opportunities. Diabetes Technol Ther 2016;18 Suppl 2:S3-13.

8. Arbeitsgemeinschaft Diabetes \& Technologie. Aktualisierte Stellungnahme der DDG-Arbeitsgemeinschaft Diabetes \& Technologie (AGDT) zum Ersatz von Blutzuckermessungen durch Messungen mit Systemen zum kontinuierlichen real-time-Glukosemonitoring (rtCGM) oder mit intermittierendem Scannen (iscCGM). DSH 2019;28:206-17.

9. Haak T, Hanaire H, Ajjan R, Hermanns N, Riveline JP, Rayman G. Flash glucose-sensing technology as a replacement for blood glucose monitoring for the management of insulin-treated type 2 diabetes: a multicenter, open-label randomized controlled trial. Diabetes Ther 2017;8:55-73.

10. Kropff J, Choudhary P, Neupane S, Barnard K, Bain SC, Kapitza $C$, et al. Accuracy and longevity of an implantable continuous glucose sensor in the PRECISE study: a 180-day, prospective, multicenter, pivotal trial. Diabetes Care 2017;40:63-8.

11. Bergenstal RM, Klonoff DC, Garg SK, Bode BW, Meredith M, Slover RH, et al. Threshold-based insulin-pump interruption for reduction of hypoglycemia. N Engl J Med 2013;369:224-32.

12. Weisman A, Bai J-W, Cardinez M, Kramer CK, Perkins BA. Effect of artificial pancreas systems on glycaemic control in patients with type 1 diabetes: a systematic review and meta-analysis of outpatient randomised controlled trials. Lancet Diabetes Endocrinol 2017;5:501-12.

13. Beck RW, Riddlesworth T, Ruedy K, Ahmann A, Bergenstal R, Haller $\mathrm{S}$, et al. Effect of continuous glucose monitoring on glycemic control in adults with type 1 diabetes using insulin injections: the DIAMOND randomized clinical trial. J Am Med Assoc 2017;317:371-8.

14. JDRF CGM Study Group. JDRF randomized clinical trial to assess the efficacy of real-time continuous glucose monitoring in the management of type 1 diabetes: research design and methods. Diabetes Technol Ther 2008;10:310-21.

15. Heinemann L, Freckmann G, Ehrmann D, Faber-Heinemann G, Guerra S, Waldenmaier D, et al. Real-time continuous glucose monitoring in adults with type 1 diabetes and impaired hypoglycaemia awareness or severe hypoglycaemia treated with multiple daily insulin injections (HypoDE): a multicentre, randomised controlled trial. Lancet 2018;391:1367-77.

16. Polonsky WH, Hessler D, Ruedy KJ, Beck RW, DIAMOND Study Group. The impact of continuous glucose monitoring on markers of quality of life in adults with type 1 diabetes: further findings from the diamond randomized clinical trial. Diabetes Care 2017;40:736-41.

17. Dunn TC, Xu Y, Hayter G, Ajjan RA. Real-world flash glucose monitoring patterns and associations between self-monitoring frequency and glycaemic measures: a European analysis of over 60 million glucose tests. Diabetes Res Clin Pract 2018;137:37-46.

18. Olafsdottir AF, Polonsky W, Bolinder J, Hirsch IB, Dahlqvist $\mathrm{S}$, Wedel $\mathrm{H}$, et al. A randomized clinical trial of the effect of continuous glucose monitoring on nocturnal hypoglycemia, daytime hypoglycemia, glycemic variability, and hypoglycemia confidence in persons with type 1 diabetes treated with multiple daily insulin injections (GOLD-3). Diabetes Technol Ther 2018;20:274-84.

19. Messer LH, Berget C, Beatson C, Polsky S, Forlenza GP. Preserving skin integrity with chronic device use in diabetes. Diabetes Technol Ther 2018;20:S254-64.
20. Freckmann G, Link M, Westhoff A, Kamecke U, Pleus S, Haug C. Prediction quality of glucose trend indicators in two continuous tissue glucose monitoring systems. Diabetes Technol Ther 2018;20:550-6.

21. Schmelzeisen-Redeker G, Schoemaker M, Kirchsteiger H, Freckmann G, Heinemann L, Del Re L. Time delay of CGM sensors: relevance, causes, and countermeasures. J Diabetes Sci Technol 2015;9:1006-15.

22. Basu A, Dube S, Veettil S, Slama M, Kudva YC, Peyser T, et al. Time lag of glucose from intravascular to interstitial compartment in type 1 diabetes. J Diabetes Sci Technol 2015;9:63-8.

23. Bailey TS, Chang A, Christiansen M. Clinical accuracy of a continuous glucose monitoring system with an advanced algorithm. J Diabetes Sci Technol 2015;9:209-14.

24. Bailey T, Bode BW, Christiansen MP, Klaff LJ, Alva S. The performance and usability of a factory-calibrated flash glucose monitoring system. Diabetes Technol Ther 2015;17: 787-94.

25. Kamath A, Mahalingam A, Brauker J. Analysis of time lags and other sources of error of the DexCom SEVEN continuous glucose monitor. Diabetes Technol Ther 2009;11:689-95.

26. Freckmann G, Link M, Pleus S, Westhoff A, Kamecke U, Haug $C$. Measurement performance of two continuous tissue glucose monitoring systems intended for replacement of blood glucose monitoring. Diabetes Technol Ther 2018;20:541-9.

27. Wadwa RP, Laffel LM, Shah VN, Garg SK. Accuracy of a factorycalibrated, real-time continuous glucose monitoring system during 10 days of use in youth and adults with diabetes. Diabetes Technol Ther 2018;20:395-402.

28. Heinemann L. Continuous glucose monitoring (CGM) or blood glucose monitoring (BGM): interactions and implications. J Diabetes Sci Technol 2018;12:873-9.

29. Kovatchev BP, Patek SD, Ortiz EA, Breton MD. Assessing sensor accuracy for non-adjunct use of continuous glucose monitoring. Diabetes Technol Ther 2015;17:177-86.

30. Gross TM, Bode BW, Einhorn D, Kayne DM, Reed JH, White $\mathrm{NH}$, et al. Performance evaluation of the MiniMed continuous glucose monitoring system during patient home use. Diabetes Technol Ther 2000;2:49-56.

31. Kirchsteiger H, Heinemann L, Freckmann G, Lodwig V, Schmelzeisen-Redeker G, Schoemaker M, et al. Performance comparison of CGM systems: MARD values are not always a reliable indicator of CGM system accuracy. J Diabetes Sci Technol 2015;9:1030-40.

32. Matuleviciene V, Joseph JI, Andelin M, Hirsch IB, Attvall S, Piv$\operatorname{odic} A$, et al. A clinical trial of the accuracy and treatment experience of the Dexcom G4 sensor (Dexcom G4 System) and Enlite sensor (guardian REAL-time system) tested simultaneously in ambulatory patients with type 1 diabetes. Diabetes Technol Ther 2014;16:759-67.

33. Freckmann G, Link M, Kamecke U, Haug C, Baumgartner B, Weitgasser R. Performance and usability of three systems for continuous glucose monitoring in direct comparison. J Diabetes Sci Technol 2019;13:890-8.

34. Bland JM, Altman DG. Statistical methods for assessing agreement between two methods of clinical measurement. Lancet 1986;327:307-10.

35. Matthaei S. Assessing the value of the ambulatory glucose profile in clinical practice. J Diabetes Vasc 2014;14:148-52. 
36. Battelino T, Danne T, Bergenstal RM, Amiel SA, Beck R, Biester $\mathrm{T}$, et al. Clinical Targets for continuous glucose monitoring data interpretation: recommendations from the international consensus on time in range. Diabetes Care 2019;42:1593-603.

37. Reynolds TM, Smellie WS, Twomey PJ. Glycated haemoglobin (HbA1c) monitoring. Br Med J 2006;333:586-8.

38. Bergenstal RM, Beck RW, Close KL, Grunberger G, Sacks DB, Kowalski A, et al. Glucose management indicator (GMI): a new term for estimating $\mathrm{A} 1 \mathrm{C}$ from continuous glucose monitoring. Diabetes Care 2018;41:2275-80.

39. Mendez CE, Mok K-T, Ata A, Tanenberg RJ, Calles-Escandon J, Umpierrez GE. Increased glycemic variability is independently associated with length of stay and mortality in noncritically ill hospitalized patients. Diabetes care 2013;36:4091-7.

40. Diabetes Control and Complications Trial Research Group, Nathan DM, Genuth S, Lachin J, Cleary P, Crofford O, et al. The effect of intensive treatment of diabetes on the development and progression of long-term complications in insulin-dependent diabetes mellitus. N Engl J Med 1993;329:977-86.
41. Heinemann L, Freckmann G, Muller-Wieland D, Kellerer M. Critical reappraisal of the time-in-range: alternative or useful addition to glycated hemoglobin? J Diabetes Sci Technol 2019. Doi: $10.1177 / 1932296819883885$ [Epub ahead of print].

42. Gorst C, Kwok CS, Aslam S, Buchan I, Kontopantelis E, Myint PK, et al. Long-term glycemic variability and risk of adverse outcomes: a systematic review and meta-analysis. Diabetes Care 2015;38:2354-69.

43. Gehr B, Holder M, Kulzer B, Lange K, Liebl A, Sahm C, et al. SPECTRUM. J Diabetes Sci Technol 2017;11:284-9.

44. Kulzer B. flash Schlungs- und Behandlungsprogramm zur Flash Glukose Messung. https://www.kirchheim-shop.de/ aerzte/PAeDIATRIE/Schulungsprogramme/Flash-Schulungsset. html.

45. Hermanns N, Ehrmann D, Schipfer M, Kröger J, Haak T, Kulzer B. The impact of a structured education and treatment programme (FLASH) for people with diabetes using a flash sensor-based glucose monitoring system: results of a randomized controlled trial. Diabetes Res Clin Pract 2019;150:111-21. 